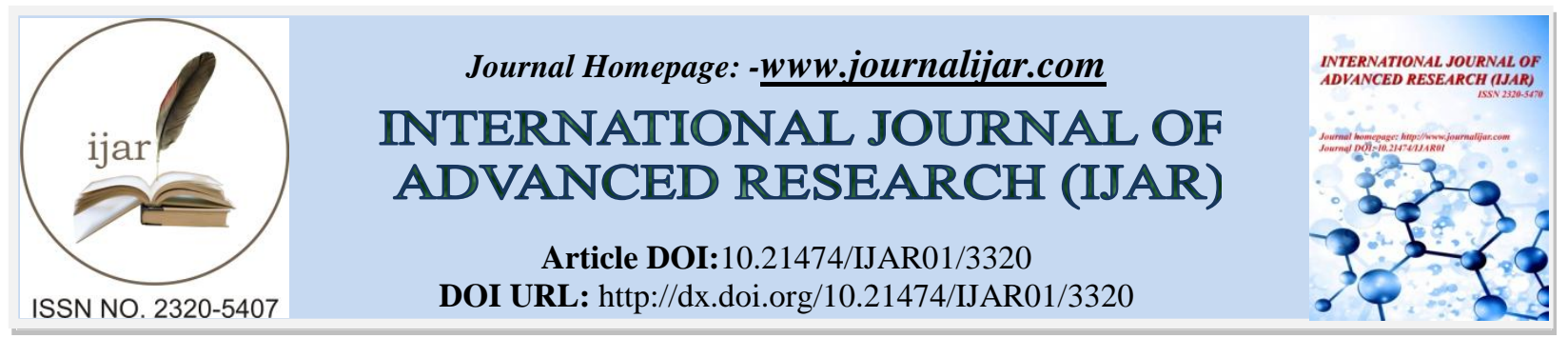

RESEARCH ARTICLE

\title{
GREEN SYNTHESIS, CYTOTOXICITY AND UTILIZATION OF CARBOXYMETHYLCHITOSAN- STABILIZED GOLD NANOPARTICLES.
}

\author{
H. M. Ibrahim ${ }^{1 *}$, A. Dakrory ${ }^{2}$, T. M. Tawfik ${ }^{3}$ and H. A. Zgeiup ${ }^{2,4}$.
}

1. Pre-Treatment \& Finishing of Cellulosic Fibers, Textile Research Division, National Research Centre, 33 El Bohouthst. (Former El Tahrir St.), Dokki, Giza, Egypt, P.O.12622.

2. Physics Department, Faculty of Girls for Arts, Science and Education, Ain Shams University, Cairo, Egypt.

3. Faculty of Applied Arts, Printing, Dyeing and Finishing Department, Benha University, Benha, Egypt.

4. Faculty of scienceEjelat, University of Zawia, Libya.

\section{Manuscript Info}

Manuscript History

Received: 27 December 2016

Final Accepted: 25 January 2017

Published: February 2017

\begin{abstract}
Gold nanoparticles (AuNPs) was prepared via simple and green method by using polysaccharides as reducing and stabilizing agents at the same time. Hiren we used carboxymethylchitosan (CMCS) as a reducing agent for gold nanoparticle as well as capping agent. CMCS prepared based on our previous method by reacting chitosan with monochloroacetic acid in alkaline medium. AuNPs were prepared by using different concentrations of carboxymethylchitosan $(0.2 \% \mathrm{w} / \mathrm{v}$, $0.5 \% \mathrm{w} / \mathrm{v}$ and $1 \% \mathrm{w} / \mathrm{v})$ at $100{ }^{\circ} \mathrm{C}$ for 1 hour. CMCS was characterized by using nitrogen content, carboxyl content and FTIR spectra. AuNPswas characterized by using UV spectrophotometry and TEM images. Finally, the cytotoxicity of the prepared AuNPs were evaluated using cell viability assay from MMT and $\mathrm{IC}_{50}$ values compared with AuNPs prepared by chemical methods. The results shows that AuNPs have normal distributed with $15-25 \mathrm{~nm}$ particle size and its cytotoxicity was lowered when prepared by this green method and can use GNPs safely in contact medical treatment with skin.
\end{abstract}

Copy Right, IJAR, 2017,. All rights reserved.

\section{Introduction:-}

Metal nanoparticles preparation represents major area in nanoscale science and engineering to give unusual physical and chemical properties specially its catalytic activity, novel electronic and magnetic properties and their potential applications in bio nanotechnology $[1,2]$.

Metal nanoparticles generally prepared by chemical reduction of metal salts with chemical reducing agents such as citric acids, borohydrides, or other organic compounds[1, 3-5].These reducing agents cause cytotoxicity towards biological hazards. Green chemistry used to minimize or eliminate the waste and implement sustainable process [6].So that biological method used for prepare AuNPs.

Raveendran et al was the first team work used the green concept to prepare silver nanoparticles by using glucose as reducing agent and starch as capping agent [7]. Nanoparticles preparation via green method was evaluated from three aspects: solvent, reducing agent and capping agent[8].

Corresponding Author: -H. M. Ibrahim.

Address:-Pre-Treatment \& Finishing of Cellulosic Fibers, Textile Research Division, National 
Chitosan as inexpensive material with renewable sources used in several applications especially in cosmetics, pharmaceuticals, food and biotechnology [9, 10]. In the preparation of gold nanoparticles by using chitosan biopolymer, the $\mathrm{NH}_{2}$ groups used to stabilize gold nanoparticles [11, 12]. However precise control needed to avoid nanoparticles aggregations[11, 13].Due to poor solubility of chitosan. Few papers found in the literature dealing with the direct application of chitosan and AuNPs nanocomposites.

Water-soluble chitosan derivative, O-carboxymethylchitosan (CMCS), not only has good solubility in water but also has unique properties (chemical, physical and biological) e.g. high viscosity, biodegradability, biocompatibility and low cytotoxicity. Herein chemical modification perform only on $\mathrm{OH}$ groups to form $\mathrm{OCH}_{2} \mathrm{COOH}$, which retain $\mathrm{NH}_{2}$ groups accessible for reaction i.e., O-CMCS has both $\mathrm{COOH}$ and $\mathrm{NH}_{2}$ groups used to stabilize AuNPs so that OCMCS used as capping agent as well as reducing agent [14].

In the present study, we used simple and green method for gold nanoparticles preparation using carboxymethylchitosan as reducing agent and capping agent at the same time. No other chemical substances needed for the reduction process. We used aqueous solution in this process to avoid environmental hazards. UV spectrophotometry and TEM imaging used to characterize the prepared AuNPs. Finally, we evaluated the cytotoxicity of these nanoparticles compared with the AUGPs prepared by common chemical reduction.

\section{Experimental:- \\ Materials:-}

Chitosan (CS) (Aldrich, viscosity 1860cps, degree of deacetylation79.0\%). Sodium hydroxide (Modern Lab chemicals), monochloroacetic (Fluka), are used without furtherpurificationAuric-chloride $\left(\mathrm{HAuCl}_{4}\right)$ purchased from Aldrich and used withoutfurther purification, USA.All other chemicals and reagents were of analytical grade, andwere used without further purification.

\section{Methods:-}

Preparation of Carboxymethylchitosan:-

The carboxymethylation of chitosan (CMCS) was preparedas reported in our previous work $[15,16]$.

\section{Preparation of Gold Nanoparticles (AuNPs):-}

Gold nanoparticle were prepared by reduction of sodium citrate method as mentioned where $[17,18]$ with some slight modifications as follow: gold (III) chloride stock solution (1\%) used to prepare $15 \mathrm{mM}, 20 \mathrm{mM}$ and $25 \mathrm{mM}$ respectively, followed by heating to $95^{\circ} \mathrm{C}$ under stirring on magnetic stirrer with heater. To this boiling solution add tri sodium citrate $(1.5 \% \mathrm{w} / \mathrm{v})$, and continue stirring until give red colour. Then we stored this solution at $4^{\circ} \mathrm{C}$ to be ready for use.

\section{Finishing of Fabrics with Gold nanoparticles:-}

The prepared gold nanoparticles (AuNPs) were applied on washed and dried fabrics using pad-dry-cure method. $30 \times 30 \mathrm{~cm}$ of fabrics were immersed in the gold nanoparticles (AuNPs) $(0.005-0.5 \mathrm{~g} / \mathrm{ml})$ solution containing acrylate binder (1\%) for $30 \mathrm{~min}$., and then it was passed through a padding mangle with $100 \%$ wet pick-up for all of the treatments. Then the fabrics were dried at $80^{\circ} \mathrm{C}$ for $5 \mathrm{~min}$., followed by thermo-fixation for at $140^{\circ} \mathrm{C}$ for $3 \mathrm{~min}$. Finally, samples washed and dried to be ready for characterization and antibacterial evaluation.

\section{Characterizations of Gold Nanoparticles (AuNPs):-}

- $\quad$ Fourier transform infrared (FT-IR) spectra of the samples were recorded by using an FT-IRspectrophotometer (Nexus 670, Nicolet, USA) in the region of $4000-400 \mathrm{~cm}^{-1}$ with spectra resolution of $4 \mathrm{~cm}^{-1}$.

- UV-vis spectroscopy of AuNPs were record on Shimadzu (UV-2450) to confirm the presence of AuNPs in the reaction medium at range $510-560 \mathrm{~nm}$.

- Shape and size of gold nanoparticles (AuNPs) were investigated using JEOL, JXA-840 electron probe microanalyzer, Japan.

- The UV-protection factor (UPF) demonstrates the ratio ofsunburn-causing UV measured without and with the protection of the fabric. The UPF of untreated and finished fabricsamples (size $3 \mathrm{~cm} \times 3 \mathrm{~cm}$ ) was determined according to the Australian/New Zealand standard (AS/NZS 4399-1996: Sun protectiveclothing-Evaluation and classification) using UV-Shimadzu 3101 PCspectrophotometer at wavelength of 280-390 nm, which includes the UVB (280-320 nm) and the UVA (320-400 nm) according to the following equation: 


$$
U P F_{i}=\frac{\sum_{\lambda=280}^{400} E_{\lambda} \times S_{\lambda} \times \Delta \lambda}{\sum_{\lambda=280}^{400} E_{\lambda} \times S_{\lambda} \times T_{\lambda} \times \Delta \lambda}
$$

where: $\mathrm{E} \lambda=$ relative erythemal spectral effectiveness, $\mathrm{S} \lambda=$ solar spectral irradiance, $\mathrm{T} \lambda=$ average spectral transmission of the specimen, and $\Delta \lambda=$ measured wavelength interval $(\mathrm{nm})$ Regarding UV -protection categories, fabrics are classified to good, very good, and excellent if their UPF values range from 15 to 24,25 to 39 , and above $40(40+)$ respectively.

- $\quad$ SEM and EDX of the treated fabrics was studied using a scanning electron probe micro analyzer (type JXA 840A)-Japan. Surface morphologies were imaged at different magnifications, using $30 \mathrm{kV}$ accelerating voltage.

The tests was carried out at the Central unit for analysis and scientific services at National Research Center.

\section{Evaluation of cytotoxicity of AuNPs:}

Cytotoxicity of the prepared AuNPs on A-549 cells were evaluated via cell viability test using MMT method (3-(4, 5-dimethylthiazol-2-yl)-2, 5-diphenyltetrazolium bromide) and determination of values of $\mathrm{IC}_{50}[19,20]$.

\section{Results and Discussion:-}

Preparation ofCarboxymethylchitosan:-

The carboxymethylation of chitosan proceeds by two step consecutive reaction and is accompanied by an undesired side reaction. In the main reaction, the sodium hydroxide reacts first with the hydroxyl groups of chitosan to give alkali chitosan. The carboxymethyl groups are then formed in a SN2 reaction between the alkali chitosan and monochloroacetic acid (MCAA). The main reaction is given by:

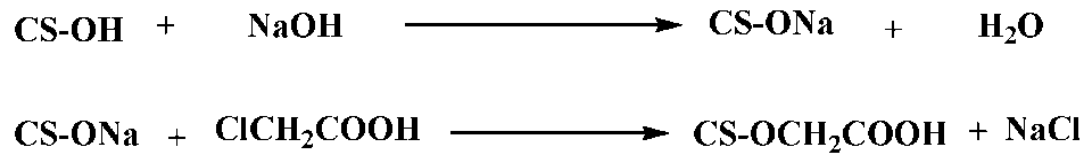

The side reaction takes place and results in the formation of sodium glycolate from MCAA and sodium hydroxide.

$$
\mathrm{NaOH}+\mathrm{ClCH}_{2} \mathrm{COOH} \longrightarrow \mathrm{HOCH}_{2} \mathrm{COONa}+\mathrm{NaCl}
$$

The FTIR spectra of the prepared CMCSs is shown in Figure 1. In IR spectrum, the wide band at $3420 \mathrm{~cm}^{-1}$ corresponds to the axial stretching of the $\mathrm{O}-\mathrm{H}$ and $\mathrm{N}-\mathrm{H}$ bonds The peaks at $2927 \mathrm{~cm}^{-1}$ and $1639 \mathrm{~cm}^{-1}$ are attributed to the axial stretching of the $\mathrm{C}-\mathrm{H}$ bonds and the symmetric stretching vibration of $\mathrm{C}=\mathrm{O}$ in the $-\mathrm{COOH}$ groups, respectively. The latter peak, together with the peak at $1420 \mathrm{~cm}^{-1}$, which arose from the asymmetric stretching vibration of the $-\mathrm{COO}^{-}$group, confirm the substitution of carboxymethyl groups onto the chitosan chain. Two bands at 1528 and $1513 \mathrm{~cm}^{-1}$ assigned to $\mathrm{NH}_{3}{ }^{+}$, indicate that the carboxymethylation occurred at $\mathrm{OH}$ positions. The peaks at 1413 and $1377 \mathrm{~cm}^{-1}$ are related to the symmetric angular deformation of $\mathrm{C}-\mathrm{H}$ bonds and $\mathrm{C}-\mathrm{N}$ stretching vibrations (amide III band), respectively. The peak at $1377 \mathrm{~cm}^{-1}$ did not increase significantly in the spectra of the CMCS, compared to the chitosan spectrum, which indicates that a significant amount of $\mathrm{N}$-carboxymethylation did not take place. The stretching vibration of $\mathrm{C}-\mathrm{O}$ in the $\mathrm{CH}_{2} \mathrm{COOH}$ group gives rise to the peak at $1207 \mathrm{~cm}^{-1}$. Peaks located in the range of $1175-878 \mathrm{~cm}^{-1}$ are the result of vibrations of $\mathrm{C}-\mathrm{O}$ and $\mathrm{C}-\mathrm{O}-\mathrm{C}$ and some other bonds that comprise the polysaccharide chain[21]. 


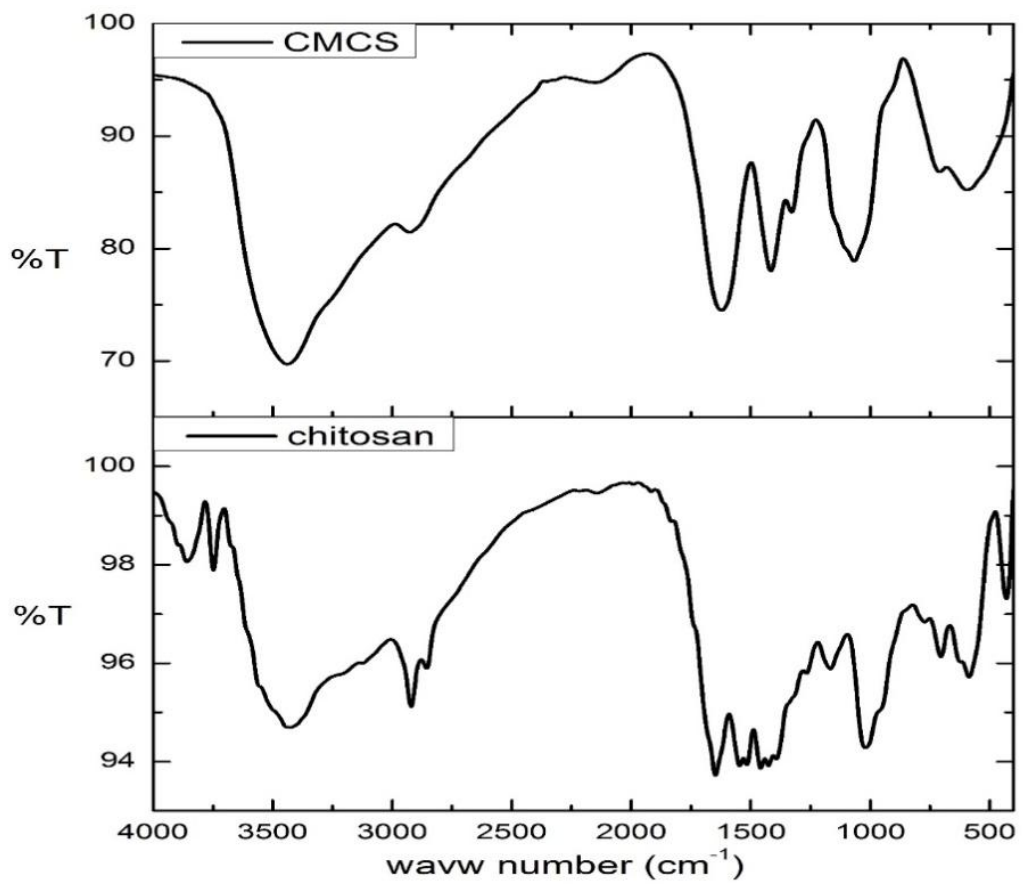

Figure 1:-FTIR spectrum of chitosan (CS) and CMCS prepared by reaction of 5gmchitosan with 2.5M MCAA in Characterization of the CMCS-AuNPs nanocomposite:the presence of $50 \% \mathrm{NaOH}$ within $3 \mathrm{hrs}$ at $60^{\circ} \mathrm{C}$.

Carboxymethylchitosan play an important role in the preparation of nanoparticles. Amino groups have been used as metal nanoparticles stabilizer [14, 22]. So that we suggest that free amino groups in O-CMCS could bind with gold nanoparticles to stabilize it. When chitosan used instead of O-CMCS to stabilize AuNPs aggregation of nanoparticles occurs due to chitosan insoluble in both neutral and alkaline medium [11, 14].

Figure 2 shows TEM images of the O-CMCS-AuNPs nanocomposites. It was observed that the AuNPs were encapsulated by O-CMCS and their size ranged from 15-25 nm. Unlike most gold colloid, few amount of nonspherical particles beside most spherical one was observed. These non-spherical particles seemed to be fabricated by gathered interference of two or three spherical particles during the nucleation process[14, 23].
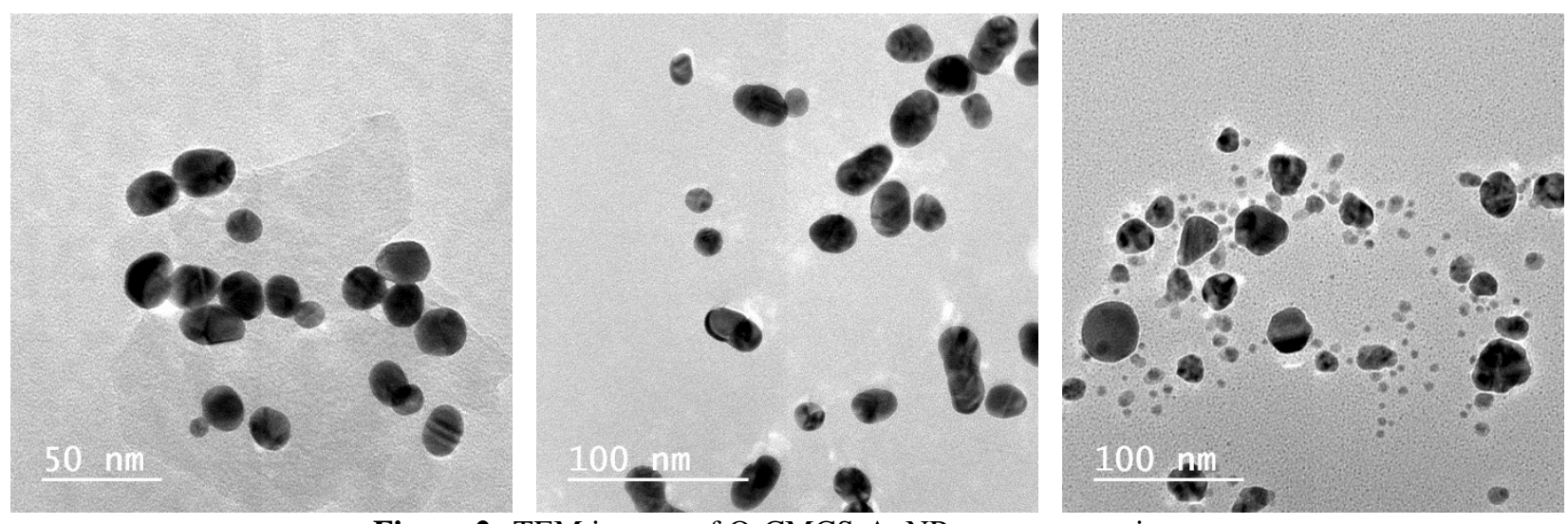

Figure 2:-TEM images of O-CMCS-AuNPs nanocomposites.

Spectrophotometry is another important aspect for characterization of gold nanoparticles. With increase in particle size, the absorption peak shifts to longer wavelength and the width of absorption spectra is related to the size distribution range (Figure 2). Generally, gold nanospheres display a single absorption peak in the visible range between 510-550 nm, because of surface Plasmon resonance and show heavy absorption of visible light at $520 \mathrm{~nm}$. This gives brilliant red color to Gold Nanoparticle (AuNPs), which varies according to their size. In present study 
the absorption of gold nanoparticle was measured in single beam spectrophotometer and absorption maxima was noted at different wavelength $(390-630 \mathrm{~nm})$.
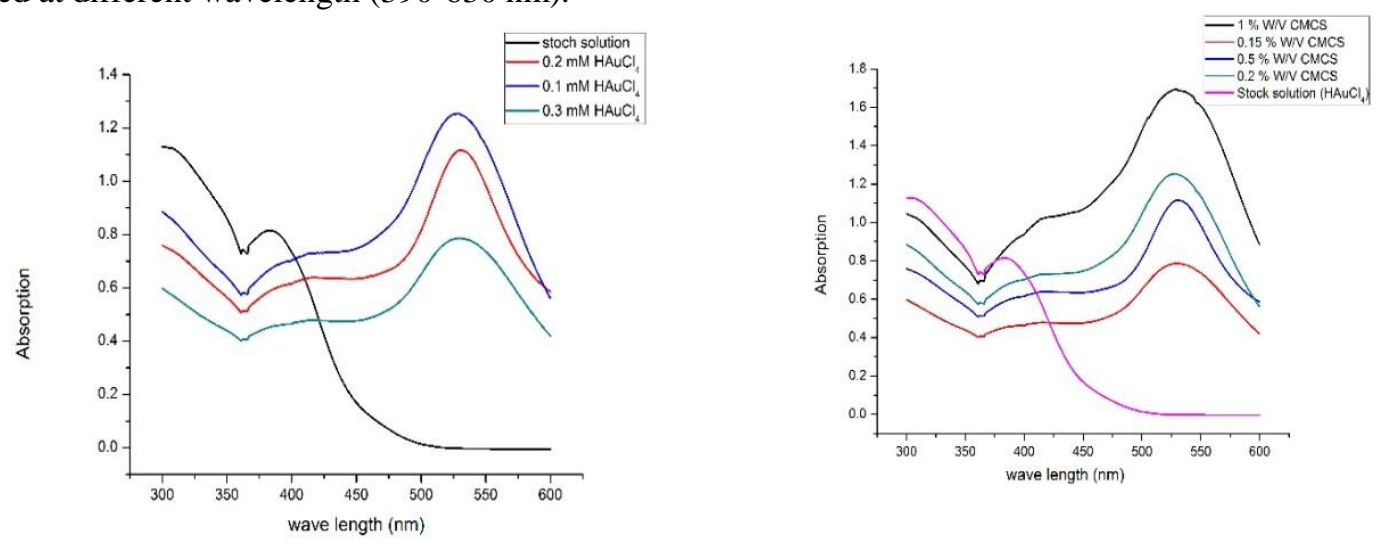

Figure 3:- UV/visible spectrum of gold nanoparticles

Figure 3 shows that the UV/visible spectrum of gold nanoparticles prepared bu using carboxymethylchitosan as reducing agent as well as capping (stabilizing) agent with fifferent gold salt concentrations $(0.1,0.2,0.3 \mathrm{mM})$ and diffeeent O-CMCS concentration $(0.15 \%, 0.2 \%, 0.5 \%$ and $1 \% \mathrm{~W} / \mathrm{V})$ to obtain the optimum condition and these results shows that the optimum condition for preparing iniform AuNPs from O-CMCS at $0.2 \%$ CMCS and $0.2 \mathrm{mM}$ $\mathrm{HAuCl}_{4}$.

\section{Finishing of Fabrics with Gold Nanoparticles:-}

We used 100\% cotton (Sample1) and 65:35 cotton: polyester (Sample 2) blende fabrics finished with the prepared gold nanoparticles (AuNPs) to be fabrics with new properties such as ultra violet protection (UPF). The results of the anti-UV efficacy of theuntreated and AUNPs loaded substrates are shown in Table 1.It demonstrates that after treatment offabrics with AuNPs results in a significant increase in theirUV-protection function. The UV-protection property of the untreated cotton and Cotton/polyester substrates showed that they afforded poor protection, UPF < 20, against UV-radiation. The variation in protection value, expressed as UPF, between the cotton and Cotton/polyester, before and after post-treatment with AuNPs, is attributed to their differences in fabric construction[24].

Table 1:-Atomic absorption and UPF values of the fabrics treated with AuNPs

\begin{tabular}{|l|c|l|}
\hline \multicolumn{1}{|c|}{ Description } & Atomic Absorption (mg/dl) & UPF \\
\hline (Sample1) untreated & 0.000 & 8.211 \\
\hline (Sample 2) untreated & 0.000 & 10.281 \\
\hline (Sample1) treated with 15 mM AuNPs & 1.203 & 20.54 \\
\hline (Sample1) treated with 15 mM AuNPs & 0.970 & 31.35 \\
\hline (Sample1)treated with 20 mM AuNPs & 1.493 & 36.12 \\
\hline (Sample 2) treated with 20 mM AuNPs & 3.841 & 48.31 \\
\hline (Sample 2) treated with 25 mM AuNPs & 3.841 & 50.65 \\
\hline (Sample 2) treated with 25 mM AuNPs & 3.630 & 61.23 \\
\hline
\end{tabular}

Scanning electron microscope (SEM/EDX) analysis were show in Figures (4), which shows the presence of Au nanoparticles in the fabrics. The surface morphology of the treated fabric with Au nanoparticles appears as smooth surface with deposit of the nanoparticles. It is clear that the prepared Au nanoparticles is more homogenous and regular distribution on the surface and has higher intensity peaks, on the other hand the Au nanoparticles EDX analysis indicate that the content of $\mathrm{Au}(0.49,0.29)$ (Au weight 0.91 ) and has lower intensity peaks [25].

The observation of the Au nanoparticles coating shows that the surface texture appears to have dense and low porosity (The choice samples were interlock). In case of ripe fabrics the nanoparticles coated the fibers and appears to be uniform in size. 
The coated fabric with Au nanoparticles film was formed and firmed on the surface of the sample. It is evident that experimental and reaction conditions did not alter the morphology surface on using Au nanoparticles. The Au nanoparticles was strongly attached to the fibers due to very strong electrostatic or chemical interactions between the Au nanoparticles and the fabric [25].
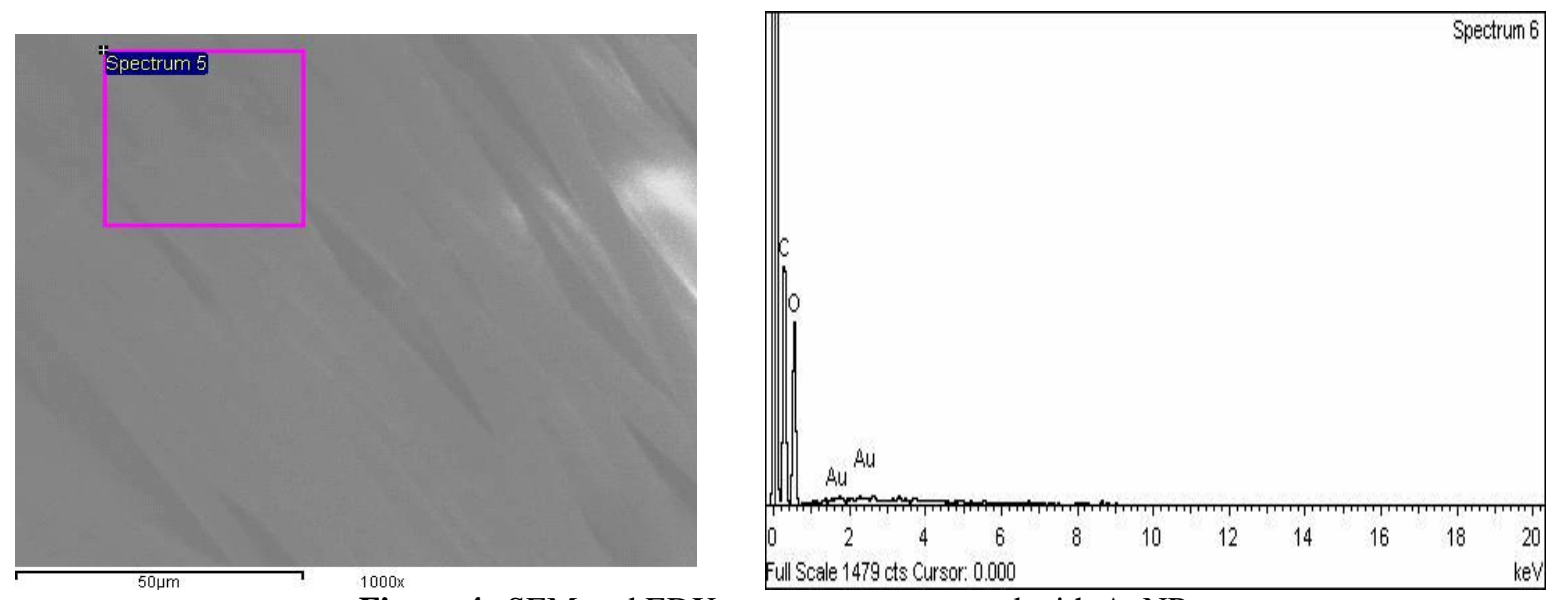

Figure 4:-SEM and EDX spectra cotton treated with AuNPs

\section{Cytotoxicity of GNPs suspensions:-}

To study the effect of gold ions concentration present in AuNPs suspensions on their toxicity, A549 cells were treated for $24 \mathrm{~h}$ with three different batches of AuNPs suspension, which contained the same concentration of GNPs $(1 \mathrm{mM})$ in three GNP types. As shown in Table. Epiderm cell line selected for cytotoxicity test for Au NPs prepared from $\mathrm{HAuCl}_{4}$ solution.

\section{Cytotoxicity evaluated using two protocols: EC50 and MTT:-}

Table 2 shows that the $\mathrm{IC}_{50}$ of $\mathrm{HAuCl} 4(1 \mathrm{mM})$, gold nanoparticles prepared by citrate reduction and third with our method using carboxymethylchitosan (CMCS). However, its toxicity reduces in AuNPs treated with CMCS. In this study, $\mathrm{Au}^{+}$decreased mitochondrial activity more than AuNPs with almost two fold difference in $\mathrm{IC}_{50}$ values as shown in Table 2, which agreed with previous studies of many researcher[25-28]

Table 2:-IC50 A549 cell line after exposing to HAuCl4, Au NPs (citrate reduction), Au NPs (CMCS reduction) (for $24 \mathrm{~h})$

\begin{tabular}{|l|l|}
\hline Material & EC50, \\
\hline HAuCl4 (1 mM) & $0.32 \mu \mathrm{g} / \mathrm{ml}$ \\
\hline Au NPs (citrate reduction) & $0.21 \mu \mathrm{g} / \mathrm{ml}$ \\
\hline Au NPs (CMCS reduction) & $5.61 \mu \mathrm{g} / \mathrm{ml}$ \\
\hline
\end{tabular}

MTT assay used to measure the cell viability expressed in the decrease in mitochondrial activity (Table3). A reduction in mitochondrial function of A549 cells exposed to the three GNPs types prepared.

Table 3:-MTT Test (metabolic Activity of the Mitochondria):

\begin{tabular}{|l|l|l|}
\hline \multirow{2}{*}{ Material } & MTT expressed in viable cells \\
\cline { 2 - 3 } & After 3hrs. & After 24 hrs. \\
\hline HAuCl4 (1 mM) & 18.6 & 2.8 \\
\hline Au NPs (citrate reduction) & 14.2 & 1.9 \\
\hline Au NPs (CMCS reduction) & 84.5 & 76.2 \\
\hline
\end{tabular}

\section{Conclusion:-}

- Gold nanoparticles (AuNPs) was prepared via simple and green method by using CMCS as reducing and stabilizing agents at the same time.

- CMCS prepared based on our previous method by reacting chitosan with monochloroacetic acid in alkaline medium. 
- AuNPs were prepared by using different concentrations of carboxymethylchitosan $(0.2 \% \mathrm{w} / \mathrm{v}, 0.5 \% \mathrm{w} / \mathrm{v}$ and $1 \%$ w/v) at $100{ }^{\circ} \mathrm{C}$ for 1 hour.

- CMCS was characterized by using nitrogen content, carboxyl content and FTIR spectra. AuNPs was characterized by using UV spectrophotometry and TEM images.

- The cytotoxicity of the prepared AuNPs were evaluated using cell viability assay from MMT and $\mathrm{IC}_{50}$ values compared with AuNPs prepared by chemical methods. The results shows that AuNPs have normal distributed with $15-25 \mathrm{~nm}$ particle size and its cytotoxicity was lowered when prepared by this green method and can use GNPs safely in contact medical treatment with skin.

\section{References:-}

1. Huang, H. and X. Yang, Synthesis of polysaccharide-stabilized gold and silver nanoparticles: a green method. Carbohydrate research, 2004. 339(15): p. 2627-2631.

2. Kabashin, A.V., et al., Fabrication and characterization of gold nanoparticles by femtosecond laser ablation in an aqueous solution of cyclodextrins. The Journal of Physical Chemistry B, 2003. 107(19): p. 4527-4531.

3. Wang, T., et al., Preparation, Characterization, and Photophysical Properties of Alkanethiols with Pyrene Units-Capped Gold Nanoparticles: Unusual Fluorescence Enhancement for the Aged Solutions of These Gold Nanoparticles. Langmuir, 2002. 18(5): p. 1840-1848.

4. Guari, Y., et al., In situ formation of gold nanoparticles within thiol functionalized HMS-C16 and SBA-15 type materials via an organometallic two-step approach. Chemistry of materials, 2003. 15(10): p. 2017-2024.

5. Ohno, K., et al., Fabrication of Ordered Arrays of Gold Nanoparticles Coated with High-Density Polymer Brushes. Angewandte Chemie International Edition, 2003. 42(24): p. 2751-2754.

6. Anastas, P.T. and J.C. Warner, Principles of green chemistry. Green chemistry: Theory and practice, 1998: p. 29-56.

7. Raveendran, P., J. Fu, and S.L. Wallen, Completely "green" synthesis and stabilization of metal nanoparticles. Journal of the American Chemical Society, 2003. 125(46): p. 13940-13941.

8. Wei, D. and W. Qian, Facile synthesis of $\mathrm{Ag}$ and Au nanoparticles utilizing chitosan as a mediator agent. Colloids and Surfaces B: Biointerfaces, 2008. 62(1): p. 136-142.

9. Croisier, F. and C. Jérôme, Chitosan-based biomaterials for tissue engineering. European Polymer Journal, 2013. 49(4): p. 780-792.

10. Sun, I.-C., et al., Biocompatible glycol chitosan-coated gold nanoparticles for tumor-targeting CT imaging. Pharmaceutical research, 2014. 31(6): p. 1418-1425.

11. dos Santos, D.S., et al., Gold nanoparticle embedded, self-sustained chitosan films as substrates for surfaceenhanced Raman scattering. Langmuir, 2004. 20(23): p. 10273-10277.

12. Zhang, N., et al., Nanocomposite hydrogel incorporating gold nanorods and paclitaxel-loaded chitosan micelles for combination photothermal-chemotherapy. International journal of pharmaceutics, 2016. 497(1): p. 210-221.

13. Huang, H., Q. Yuan, and X. Yang, Morphology study of gold-chitosan nanocomposites. Journal of colloid and interface science, 2005. 282(1): p. 26-31.

14. Xu, Q., et al., Direct electrochemistry of horseradish peroxidase based on biocompatible carboxymethyl chitosan-gold nanoparticle nanocomposite. Biosensors and Bioelectronics, 2006. 22(5): p. 768-773.

15. Abou-Zeid, N.Y., et al., CARBOXYMETHYLCHITOSAN/VISCOSE BLENDED

FILMS: PREPARATION, CHARACTERIZATION

AND ANTIBACTERIAL PROPERTIES. Journal of Materials Science and Engineering with Advanced Technology, 2013. 7(2): p. 93-123.

16. Ibrahim, H., et al., Carboxymethyl Chitosan Electrospun Nanofibers: Preparation and its Antibacterial Activity. Journal of Textile \& Apparel Technology \& Management (JTATM), 2015. 9(2).

17. DiScipio, R.G., Preparation of colloidal gold particles of various sizes using sodium borohydride and sodium cyanoborohydride. Analytical biochemistry, 1996. 236(1): p. 168-170.

18. Verma, H.N., P. Singh, and R. Chavan, Gold nanoparticle: synthesis and characterization. Veterinary world, 2014. 7(2): p. 72-77.

19. Farag, S., et al., Impregnation of silver nanoparticles into bacterial cellulose: Green synthesis and cytotoxicity. International Journal of ChemTech Research, 2015. 8(12): p. 651-661.

20. Mosmann, T., Rapid colorimetric assay for cellular growth and survival: application to proliferation and cytotoxicity assays. Journal of immunological methods, 1983. 65(1-2): p. 55-63. 
21. Abou-Zeid, N., et al., CARBOXYMETHYLCHITOSAN/VI SCOSE BLENDED FILMS: PREPARATION, CHARACTERIZATION AND ANTIBACTERIAL PROPERTIES. Journal of Materials Science and Engineering with Advanced Technology, 2013. 7(2): p. 93-123.

22. Selvakannan, P., et al., Capping of gold nanoparticles by the amino acid lysine renders them water-dispersible. Langmuir, 2003. 19(8): p. 3545-3549.

23. Bharathi, S., N. Fishelson, and O. Lev, Direct synthesis and characterization of gold and other noble metal nanodispersions in sol-gel-derived organically modified silicates. Langmuir, 1999. 15(6): p. 1929-1937.

24. Ibrahim, N.A., B.M. Eid, and M.S. Abdel-Aziz, Green synthesis of AuNPs for eco-friendly functionalization of cellulosic substrates. Applied Surface Science, 2016. 389: p. 118-125.

25. Goncalves, G., et al., Surface modification of graphene nanosheets with gold nanoparticles: the role of oxygen moieties at graphene surface on gold nucleation and growth. Chemistry of Materials, 2009. 21(20): p. 47964802.

26. Lanone, S., et al., Comparative toxicity of 24 manufactured nanoparticles in human alveolar epithelial and macrophage cell lines. Particle and fibre toxicology, 2009. 6(1): p. 1.

27. Miura, N. and Y. Shinohara, Cytotoxic effect and apoptosis induction by silver nanoparticles in HeLa cells. Biochemical and biophysical research communications, 2009. 390(3): p. 733-737.

28. Foldbjerg, R., D.A. Dang, and H. Autrup, Cytotoxicity and genotoxicity of silver nanoparticles in the human lung cancer cell line, A549. Archives of toxicology, 2011. 85(7): p. 743-750. 